\title{
Free and forced vibration analysis of rectangular/ circular/annular plates made of carbon fiber- carbon nanotube-polymer hybrid composites
}

https://doi.org/10.1515/secm-2017-0279

Received August 17, 2017; accepted April 24, 2018; previously published online August 3, 2018

\begin{abstract}
A multiscale finite element method is adopted in this paper to study the vibrational characteristics of polymer matrix composite plates reinforced with the combination of carbon fibers (CFs) and carbon nanotubes (CNTs). The effects of nanoscale and microscale are coupled through a two-step procedure. In the first step, random dispersion of CNTs into the polymer matrix is modelled using a three-phase representative volume element (RVE). In the selected RVE, the influence of the interphase formed because of non-bonded interactions between the polymer matrix and CNTs is taken into account. In the second step, the distribution of CFs into the composite is modelled, and the elastic properties of CF-CNT-polymer matrix hybrid composite are calculated for various values of volume fractions of reinforcement phases. Then, the free and forced vibration behaviors of composite plates are analyzed. It is considered that the plates have rectangular, circular, and annular shapes and are under clamped/simply supported edge conditions. The effects of CNT/CF reinforcement on the elastic modulus and density of composite and on the free/forced vibration response of the considered structures are investigated. It is shown that the vibrational behavior of plates is significantly affected by the hybrid reinforcement with CNT and CF.
\end{abstract}

Keywords: carbon nanotube; forced vibration; hybrid polymer nanocomposite; multiscale modeling; plate.

\section{Introduction}

Since the discovery of carbon nanotubes (CNTs) by Iijima in 1991 [1], these cylindrical carbon molecules have attracted

\footnotetext{
*Corresponding author: Hessam Rouhi, Department of Engineering Science, Faculty of Technology and Engineering, East of Guilan, University of Guilan, P.C. 44891-63157, Rudsar-Vajargah, Iran, Tel./Fax: +9813 42688447, e-mail: h_rouhi@guilan.ac.ir Masoud Ahmadi and Reza Ansari: Department of Mechanical Engineering, University of Guilan, P.O. Box 3756, Rasht, Iran
}

Ә Open Access. (Gc)BY $\odot 2019$ Walter de Gruyter GmbH, Berlin/Boston a lot of interest from the researchers due to their unusual properties. Owing to the covalent $s p^{2}$ bonds between the carbon atoms, CNTs are the strongest and stiffest materials yet discovered in terms of tensile strength and Young's modulus, respectively. For example, experiments of Yu et al. [2] revealed that the tensile strength of multiwalled CNTs is $63 \mathrm{GPa}$. Also, on the basis of bending tests on individual CNTs, Demczyk et al. [3] obtained their elastic modulus equal to $0.9 \mathrm{TPa}$.

Owing to the excellent mechanical properties of CNTs, they are extensively utilized to reinforce advanced composite materials [4-7]. It has been proved that CNT reinforcement has a considerable effect on the mechanical performance of CNT-reinforced composites (CNTRCs). In this regard, Esawi and Farag [8] indicated that the maximum Young's modulus that can be obtained for carbon fiber (CF)-reinforced epoxy is $167.2 \mathrm{GPa}$, while the Young's moduli of (epoxy $+20 \%$ CNT) and (epoxy $+15 \%$ $\mathrm{CNT}+50 \% \mathrm{CF}$ ) are 425.6 and $431.2 \mathrm{GPa}$, respectively.

Up to now, extensive research has been presented into the properties and behavior of CNTRCs. Using molecular dynamics simulations, Xiang et al. [9] studied the strengthening and deformation mechanisms of the aligned dispersion of single-walled CNTs in Al/CNT composites. Their results showed that the fracture behavior of $\mathrm{Al} / \mathrm{CNT}$ composite is primarily governed by the morphology of CNTs. Alva et al. [10] developed a micromechanical model to obtain the effective moduli of CNTRCs. They employed a statistical method so as to consider the random fiber orientation. On the basis of the micromechanical simplified unit cell model, Ansari and Hassanzadeh Aghdam [11] investigated the viscoelastic behavior of CNTRCs under uniaxial and biaxial loading conditions. Ansari and co-workers [12] analyzed the influence of CNT waviness on the elastic response of CNTRCs by means of a three-dimensional unit cell-based micromechanical model. The fracture behavior of CNT-reinforced poly(methyl methacrylate) matrix composites under tension was studied by Arash et al. [13] via molecular dynamics simulations. Kundalwal and Ray [14] estimated the thermoelastic properties of CNT-reinforced polymer (RP) nanocomposites using the method of cell. Also, there are several other research works in which the problems of mechanical behaviors (e.g. vibration, 
buckling, and bending) of structural elements including beams, plates, and shells made of CNTRCs and other materials have been addressed [15-25].

CNT/CF hybrid multiscale composites have been the subject of several papers because of their excellent properties and performance [26-31]. Through experimental tests, Thostenson et al. [26] found that the presence of CNTs at the fiber/matrix interface of CNT/CF hybrid multiscale composites improves the interfacial shear strength of the material. In another experimental study, Bekyarova et al. [27] indicated that these multiscale hybrid composites possess enhanced out-of-plane mechanical and electrical properties. On the basis of their interesting properties, CNT/CF hybrid multiscale composites can have several applications. For example, the application of plates made of CNT/CF hybrid multiscale composites in solar still systems has been reported in [32]. To the authors' knowledge, the vibrational characteristics of plates made of such composite materials have not been studied hitherto. As understanding the vibrational behavior of CF/CNTreinforced composite structural elements such as plates may be important in their present and future applications, the present work is devoted to address this problem. The subject of this article is studying the free and forced vibrations of circular, annular, and rectangular plates made of CNT/CF-RP under simply supported and clamped boundary conditions. To this end, a multiscale finite element method is utilized with the capability of capturing coupled nanoscale and microscale effects. First, Young's modulus and density of composite are obtained for different volume fractions of CNTs and CFs. The selected representative volume element (RVE) for the dispersion of CNTs into the polymer matrix consists of three phases including CNTs, the interphase region, and the polymer matrix. The interphase region is considered because of van der Waals interactions between nanotubes and matrix. Thereafter, the natural frequencies and amplitude-frequency curves of the composite plates are obtained for various states of reinforcement, and the results are discussed.

\section{Multiscale modeling procedure}

At first, a multiscale finite element method [33] is used to determine the elastic modulus and density of CNT-RP, CF-RP, and hybrid CNT-CF-RP. The polymer matrix is assumed to be polyimide whose Young's modulus and density are equal to $4.2 \mathrm{GPa}$ and $1310 \mathrm{~kg} / \mathrm{m}^{3}$, respectively [34]. The volume fractions of CNT are assumed to be $1 \%$, $3 \%$, and $5 \%$. In addition, the volume fractions of $\mathrm{CF}$ are considered as 5\%, 10\%, and 20\%. Nine states are also considered for the hybrid reinforcement.

First, the dispersion of CNTs into the polyimide is modeled. The RVE of this step of modeling includes three phases: CNTs, polymer matrix, and interphase. It is considered that all CNTs are covered by interphase region, which is due to van der Waals interactions. On the basis of previous studies [35-38], it has been proved that CNTs are transversely isotropic. Therefore, they are modeled as transversely isotropic materials herein with the properties given in Table 1. The presented properties in Table 1 are longitudinal Young's modulus, transverse Young's modulus, longitudinal Poisson's ratio, transverse Poisson's ratio, longitudinal shear modulus, and mass density. Furthermore, the polymer matrix and interphase are considered to be isotropic. The coordinates and orientation of distributed CNTs are assumed to be random. It should be noted that the positions of CNTs are determined in such a way that no overlapping occurs between them. Also, CNTs are dispersed in the polymer matrix homogenously without aggregation. As CNTs are dispersed into the polymer matrix, the equivalent properties are calculated.

In the second step, the RVE model of nanocomposite with random $\mathrm{CF}$ distribution is considered (secondary reinforcement). Similar to CNTs, CFs are modeled as transversely isotropic materials with the properties tabulated in Table 1. Moreover, CFs are randomly distributed into the RVE model of nanocomposite without any overlap. Figure 1 shows a schematic view of the multiscale modeling of an annular plate made of CNT-CF-RP.

Two-dimensional unit cells are employed to model the RVEs of nanocomposites. In each case, 50 particles (CNTs with diameter of $0.78 \mathrm{~nm}$ and aspect ratio of 100; CFs with diameter of $10 \mu \mathrm{m}$ and aspect ratio of 10) are dispersed in the polyimide matrix. In the two-dimensional modeling, the particles are modeled as rectangles. The smaller side length of the particles is considered as their diameter. Besides, the larger side length of the particles is calculated on the basis of the particles' aspect ratio (the ratio of the length to diameter). The side length of the square RVEs is computed using the geometrical parameters of the particle and particle's volume fraction in the polymer

Table 1: Material properties of CNT, interphase, CF, and polyimide.

\begin{tabular}{lrrrrrr}
\hline Material & $E_{\mathrm{L}}(\mathrm{GPa})$ & $\boldsymbol{E}_{\mathrm{T}}(\mathrm{GPa})$ & $\boldsymbol{v}_{\mathrm{L}}$ & $\boldsymbol{v}_{\mathrm{T}}$ & $\boldsymbol{G}_{\mathrm{L}}(\mathrm{GPa})$ & $\boldsymbol{\rho}\left(\mathrm{kg} / \mathrm{m}^{3}\right)$ \\
\hline CNT [35] & 1382.5 & 645 & 0.272 & 0.2 & 1120 & 1300 \\
Interphase [35] & 19.29 & 19.29 & 0.34 & 0.34 & 7.2 & 1305 \\
CF [39] & 294 & 18.5 & 0.27 & 0.3 & 25 & 1760 \\
Polyimide [34] & 4.2 & 4.2 & 0.4 & 0.4 & 1.5 & 1310 \\
\hline
\end{tabular}




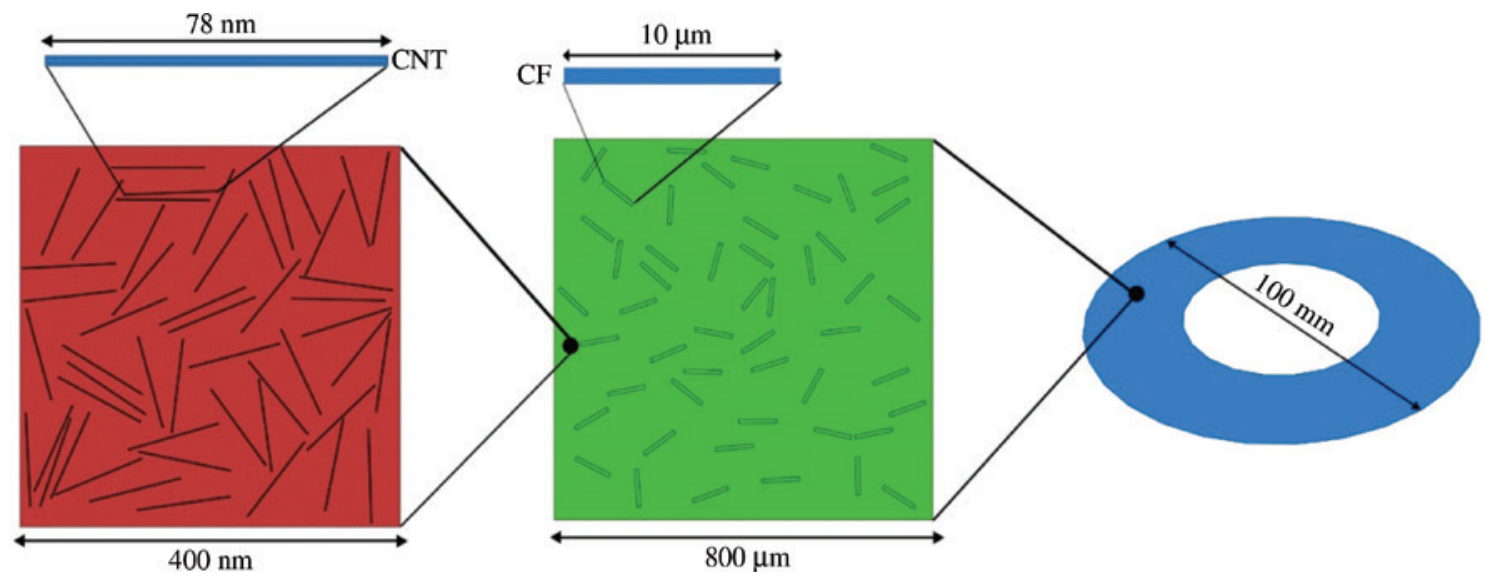

Figure 1: Multiscale modeling of CF-CNT-polymer hybrid annular composite plate.

matrix. For example, a CNT-reinforced RVE with a volume percentage of $3 \%$ has a length side equal to $318.4 \mathrm{~nm}$.

In order to calculate the elastic modulus, a uniaxial tensile test is done on the RVEs. The boundary and loading conditions are considered according to Figure 2. The stress distribution contour can be seen in this figure. Through measuring the fixed boundary reaction force and computing stress value $(\sigma)$, the equivalent elastic modulus $(E)$ of RVE is calculated using Hooke's law as

$$
E=\sigma / \varepsilon
$$

in which $\varepsilon$ denotes the RVE strain in the load direction. One side of the RVEs is constrained, and the strain of 0.02 is applied to the opposite side. In order to reduce the effect of chance on account of random dispersion, the results are generated using average values of three analyses with different random microstructures for each reinforcement.

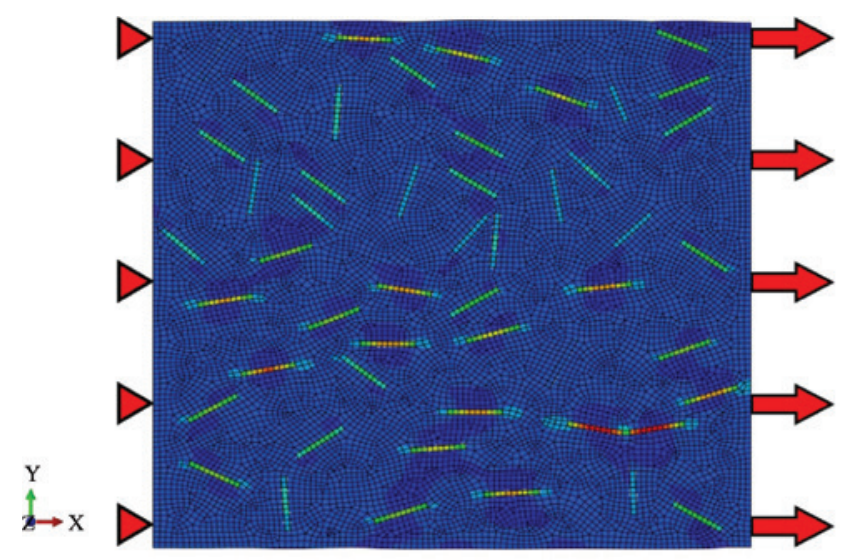

Figure 2: Tensile test for obtaining the elastic modulus of nanocomposite.
The following nonlinear elements are used: eightnode biquadratic plane stress quadrilateral element at microscale and eight-node doubly curved thick shell element at macroscale.

Examples of meshing are illustrated in Figures 3 and 4 for RVEs and plates with rectangular/circular/annular shapes. The number of elements for each RVE is about 50,000 and for plates is about 500 .

\section{Results and discussion}

First of all, in order to show the validity of the present finite element approach, comparisons are provided with the experimental results reported in [40] and those obtained from micromechanical models developed in [41] for Young's modulus of CNT-reinforced polypropylene with randomly oriented reinforcements. The outcomes of this validation study can be found in Table 2. This table gives the normalized elastic modulus of CNT-reinforced polypropylene for various values of CNT volume fraction. It is observed that the present finite element method is capable of predicting the available results with a good accuracy.

Now, the results for the properties of CNT-RP, CF-RP, and CNT-CF-RP are given in Table 3 and discussed. Three states of reinforcement are considered for CNT- and CF-RP, and nine states are considered for the hybrid reinforcement. To generate these results, the aspect ratio of CFs is assumed to be equal to 10 with a diameter equal to $10 \mu \mathrm{m}$. Furthermore, the aspect ratio and diameter of CNTs are chosen as 100 and $0.78 \mathrm{~nm}$, respectively. The thickness of interphase is also taken as $0.3333 \mathrm{~nm}$ (it is assumed that all CNTs are covered by interphase). 
A

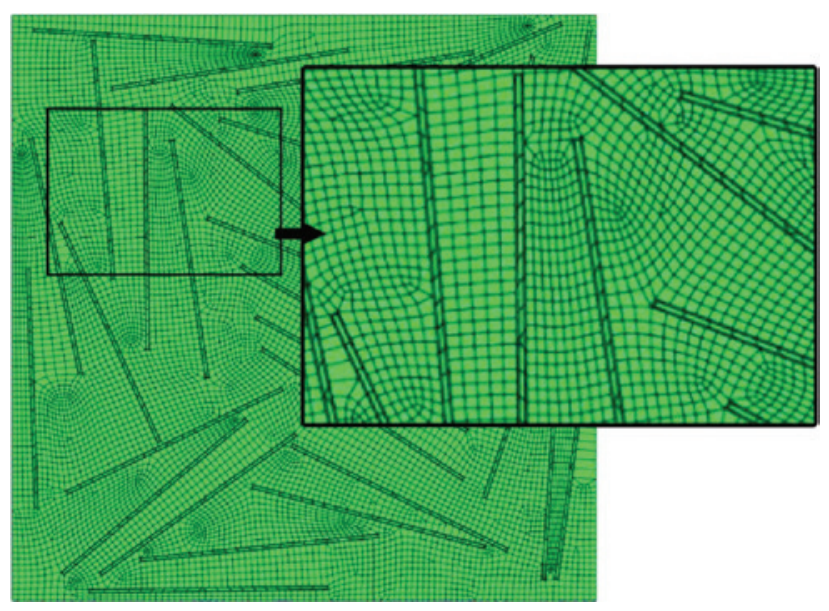

B

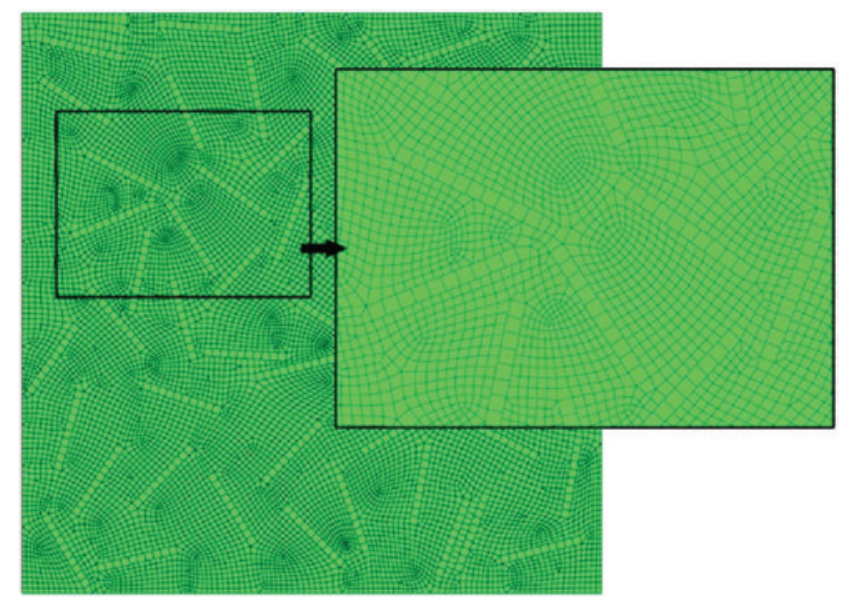

Figure 3: Meshed RVE for (A) CNT-RP and (B) CF-RP.
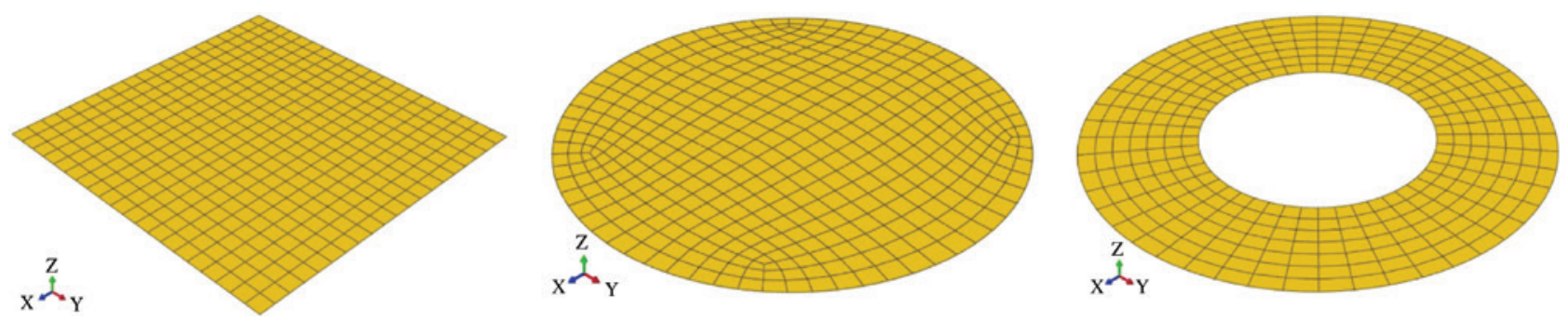

Figure 4: Meshed plates.

Table 2: Normalized elastic modulus of CNT-reinforced polypropylene with randomly oriented reinforcements (aspect ratio $=100$ ).

\begin{tabular}{lrrrr}
\hline CNT volume fraction (\%) & Present finite element method & Experiment [40] & Two-level model [41] & Two-step model [41] \\
\hline 1.6 & 1.161 & 1.19 & 1.18 & 1.13 \\
3.2 & 1.319 & 1.29 & 1.36 & 1.25 \\
4.8 & 1.526 & 1.39 & 1.54 & 1.38 \\
\hline
\end{tabular}

In Table 3, the equivalent elastic modulus and density of different composite materials are presented. The elastic modulus and density of polymer matrix are also given in this table for comparison. The stiffening of material by reinforcement with CNT/CF is clearly seen. According to Table 3, the elastic moduli of 20\% CF-RP and 5\% CNT-RP are respectively $63 \%$ and $88 \%$ larger than that of polyimide (neat material). This increase reaches 192\% in the case of 4\% CNT-20\% CF-RP, which shows that the stiffness of composite can be significantly improved by the hybrid CNT/CF reinforcement.

To perform the vibration analysis, the following geometrical properties are considered:
(a) Circular plate: $R=50 \mathrm{~mm}$
(b) Annular plate: $R_{\mathrm{o}}=50 \mathrm{~mm}, R_{\mathrm{i}}=25 \mathrm{~mm}$
(c) Square plate: $a=100 \mathrm{~mm}$

where $R, R_{\mathrm{o}}, R_{\mathrm{i}}$, and $a$ stand for the radius of circular plate, outer and inner radii of annular plate, and length of square plate, respectively. The thickness of plates is also taken as $1 \mathrm{~mm}$. Furthermore, the plates are assumed to be under clamped (C) and simply supported (S) boundary conditions.

The results of free vibration analysis are presented in Table 4. The fundamental frequencies of circular, annular, and square plates made from polyimide and CNT/CF-reinforced polyimide are tabulated in this table for clamped and simply supported edge supports. As expected, the plates vibrate with larger frequencies when they are reinforced with CFs and CNTs. For example, considering the vibrations of simply supported annular plate, the fundamental frequencies $23 \%, 10 \%$, and $32 \%$ increase as 
Table 3: Equivalent properties of CNT/CF-reinforced polyimide.

\begin{tabular}{lrr}
\hline Material & $\boldsymbol{E}(\mathrm{GPa})$ & $\boldsymbol{\rho}\left(\mathrm{kg} / \mathrm{m}^{3}\right)$ \\
\hline Polyimide & 4.200 & 1310 \\
$1 \%$ CNT-RP & 4.830 & 1309.9 \\
$3 \%$ CNT-RP & 6.411 & 1309.6 \\
$5 \%$ CNT-RP & 7.898 & 1309.3 \\
$5 \%$ CF-RP & 4.777 & 1332.5 \\
$10 \%$ CF-RP & 5.314 & 1355.0 \\
$20 \%$ CF-RP & 6.868 & 1400.0 \\
$0.95 \%$ CNT-5\% CF-RP & 5.483 & 1332.4 \\
$2.85 \%$ CNT-5\% CF-RP & 7.242 & 1332.1 \\
$4.75 \%$ CNT-5\% CF-RP & 8.884 & 1331.8 \\
$0.9 \%$ CNT-10\% CF-RP & 6.090 & 1354.9 \\
$2.7 \%$ CNT-10\% CF-RP & 8.015 & 1354.6 \\
$4.5 \%$ CNT-10\% CF-RP & 9.798 & 1354.4 \\
$0.8 \%$ CNT-20\% CF-RP & 7.827 & 1399.9 \\
$2.4 \%$ CNT-20\% CF-RP & 10.165 & 1399.7 \\
$4 \%$ CNT-20\% CF-RP & 12.284 & 1399.4 \\
\hline
\end{tabular}

the material changes from polyimide to 3\% CNT-RP, 10\% CF-RP, and 0.8\% CNT-20\% CF-RP, respectively. The effect of boundary conditions on the frequencies of plates is also observed in Table 4.

Table 4: Fundamental frequencies $(\mathrm{Hz})$ of plates with different shapes and made of various materials.

\begin{tabular}{lllll}
\hline Material & \multicolumn{2}{c}{ Circular } & & \multicolumn{2}{c}{ Annular } & & \multicolumn{2}{r}{ Square } \\
C & S & C S S
\end{tabular}

\begin{tabular}{lllllll}
\hline Polyimide $\quad 366.36$ & 182.25 & 3161.9 & 1429.3 & 322.56 & 176.44
\end{tabular} $\begin{array}{llllllll}1 \% \text { CNT-RP } & 392.89 & 195.45 & 3390.9 & 1532.8 & 345.95 & 189.21\end{array}$

$\begin{array}{lllllll}3 \% \text { CNT-RP } & 452.70 & 225.21 & 3907.1 & 1766.2 & 398.58 & 218.02\end{array}$

$\begin{array}{lllllll}5 \% \text { CNT-RP } & 502.53 & 249.99 & 4337.1 & 1960.3 & 442.45 & 242.01\end{array}$

$\begin{array}{lllllll}5 \% \text { CF-RP } & 387.40 & 192.72 & 3343.5 & 1511.4 & 341.09 & 186.57\end{array}$

$\begin{array}{lllllll}10 \% \text { CF-RP } \quad 405.19 & 201.57 & 3497.1 & 1580.8 & 356.75 & 195.14\end{array}$

20\% CF-RP $\quad \begin{array}{llllllll}453.18 & 225.44 & 3911.2 & 1768.1 & 399.00 & 218.25\end{array}$

$0.95 \%$ CNT-5\% $\quad 415.06 \quad 206.48 \quad 3582.2 \quad 1619.3 \quad 365.44 \quad 199.89$ CF-RP

$2.85 \%$ CNT-5\% $\quad 477.07 \quad 237.33 \quad 4117.4 \quad 1861.3 \quad 420.03 \quad 229.75$ CF-RP

$4.75 \%$ CNT-5\% $\quad 528.45 \quad 262.89 \quad 4560.8 \quad 2061.7 \quad 465.27 \quad 254.50$ CF-RP

$0.9 \%$ CNT-10\% $\quad 433.79 \quad 215.80 \quad 3743.8 \quad 1692.4 \quad 381.92 \quad 208.91$ CF-RP

$2.7 \%$ CNT-10\% $\quad 497.70 \quad 247.59 \quad 4295.4 \quad 1941.7 \quad 438.20 \quad 239.69$ CF-RP

4.5\% CNT-10\% $550.32 \quad 273.77 \quad 4749.6 \quad 2147.0 \quad 484.53 \quad 265.03$ CF-RP

$0.8 \%$ CNT-20\% $\quad 483.80 \quad 240.68 \quad 4175.5 \quad 1887.5 \quad 425.96 \quad 233.00$ CF-RP

$2.4 \%$ CNT-20\% $551.39 \quad 274.30 \quad 4758.8 \quad 2151.2 \quad 485.46 \quad 265.54$ CF-RP

4\% CNT-20\% $\quad 606.20 \quad 301.57 \quad 5231.9 \quad 2365.1 \quad 533.73 \quad 291.94$ CF-RP

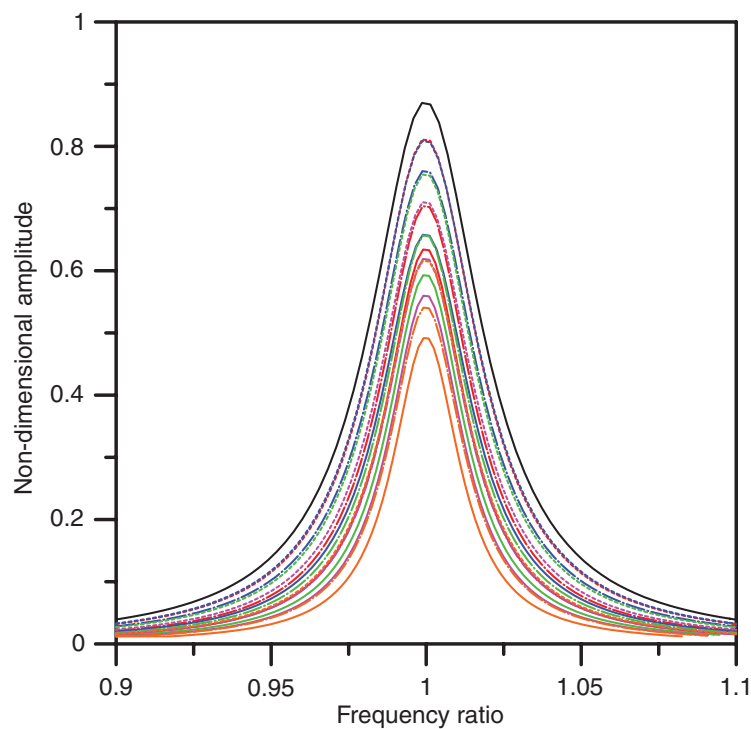

Figure 5: Forced vibration behavior of clamped circular plate.

The forced vibration behavior of plates is studied under a uniform transverse harmonic load with a magnitude of $1 \mathrm{kPa}$. The corresponding results are provided in Figures 5-7 in which the dimensionless amplitude of vibration is plotted vs. natural frequency to resonant frequency ratio (frequency ratio). The vibration amplitude is normalized with respect to the maximum amplitude (related to Figure 7). The amplitude-frequency ratio curves are obtained for 16 considered materials whose legend is given in Figure 8. The results reveal that the CF/CNT reinforcement has a significant effect on the forced vibration response of plates. To better indicate such effect, a close

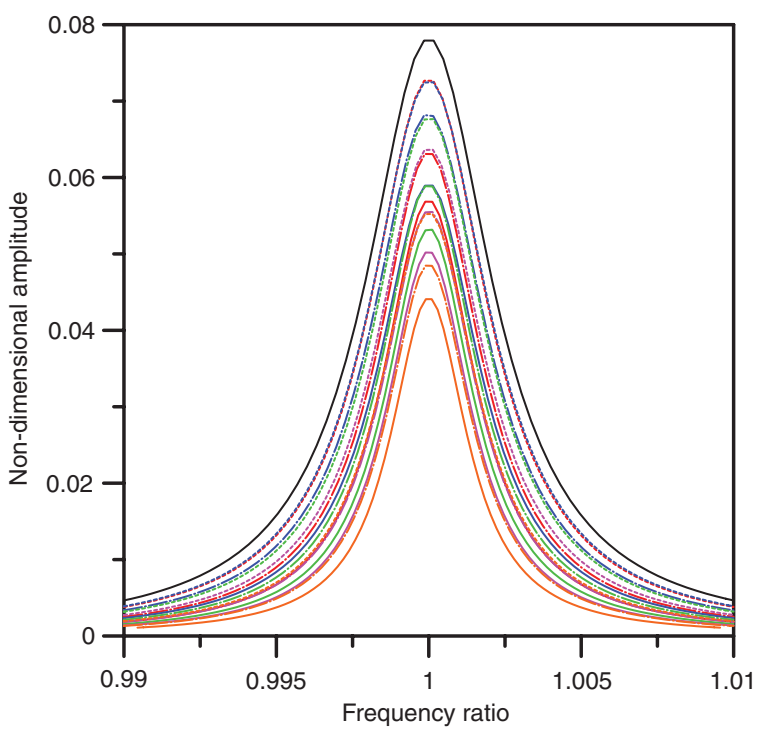

Figure 6: Forced vibration behavior of clamped annular plate. 


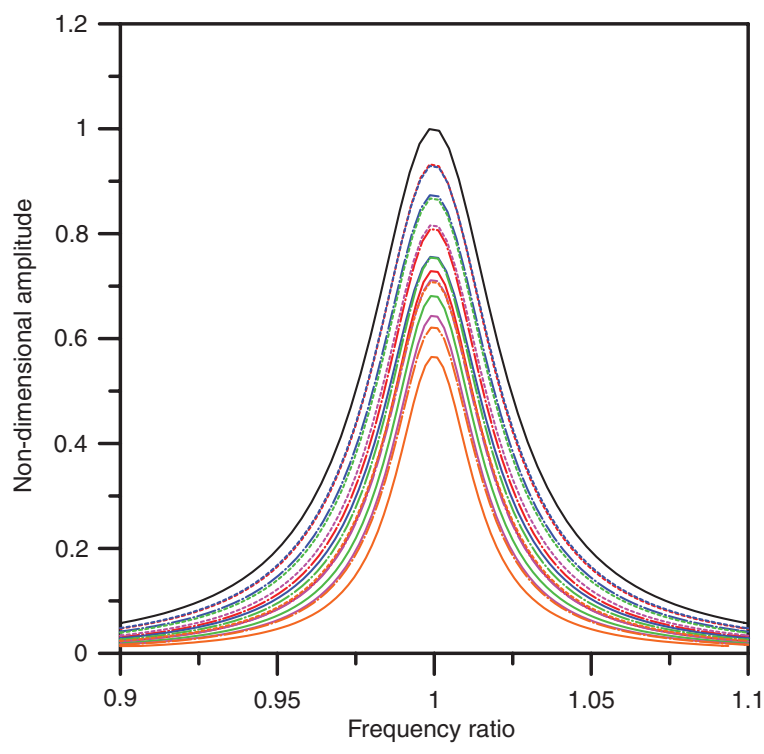

Figure 7: Forced vibration behavior of clamped square plate.

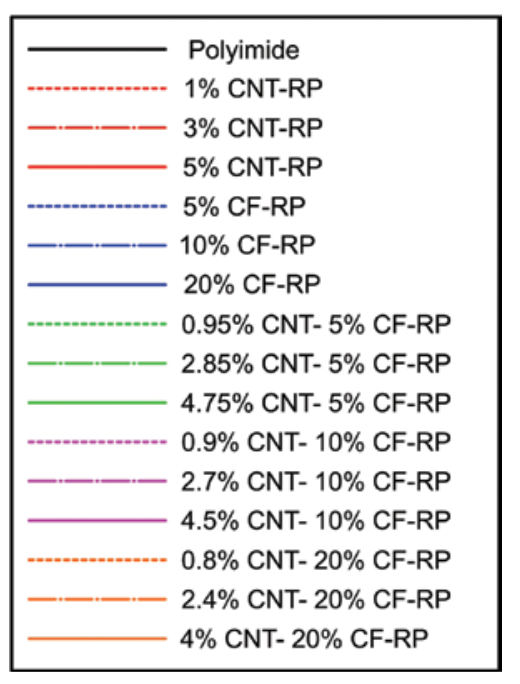

Figure 8: Legend of Figures 5-7.

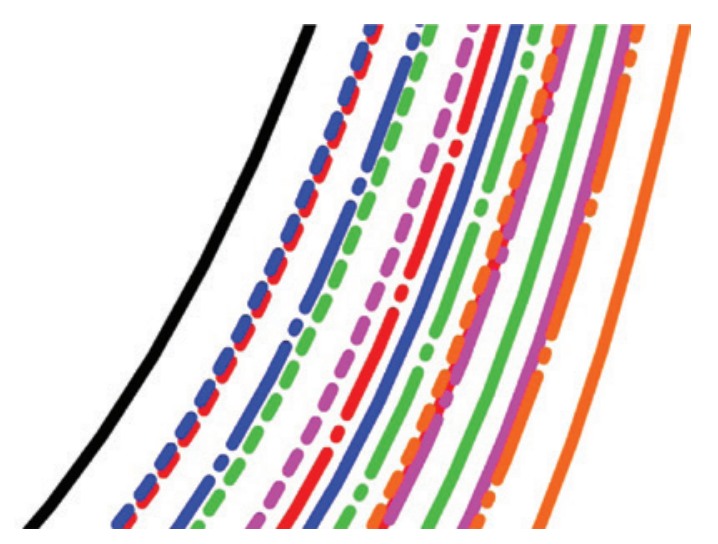

Figure 9: A close view of amplitude-frequency ratio curves for clamped circular plate. view of amplitude-frequency ratio curves for clamped circular plate is shown in Figure 9. One can find that at a given frequency ratio, the vibration amplitude decreases as the CNTs and CFs are added to the polymer matrix. The minimum values of amplitude are obtained for $4 \%$ CNT-20\% CF-RP, as expected. Moreover, it is observed that the influence of reinforcement is more prominent at a frequency ratio $=1$.

\section{Conclusion}

On the basis of a multiscale finite element approach, the free and forced vibration characteristics of composite square, annular, and circular plates were investigated. The composite was assumed to be made of CNT/CF-RP matrix. To obtain the elastic modulus and density of this hybrid multiscale composite, tensile tests were carried out on RVEs with the consideration of interphase between CNTs and the polymer matrix. The dispersions of CFs and CNTs into the polymer matrix were also assumed to be random from the viewpoints of coordinates and orientation. The properties of nanocomposite were computed for 15 states of reinforcement including three states of CNT reinforcement, three states of $\mathrm{CF}$ reinforcement, and nine states of CNT/CF hybrid reinforcement. It was revealed that the stiffness of nanocomposite can be considerably enhanced through the hybrid CNT/CF reinforcement. After that, the finite element modeling of vibrations of plates made of analyzed composite materials was performed for the clamped and simply supported boundary conditions. The free vibration analysis indicated that one can significantly reduce the resonant frequency of polymeric plates by reinforcing them with the combination of CNTs and CFs. Additionally, by studying the forced vibration curves of composite plates, one can conclude that the influence of CNT/CF reinforcement on the vibration amplitude is considerable (which is a decreasing effect) especially at resonance.

\section{References}

[1] lijima S. Nature 1991, 354, 56-58.

[2] Yu MF, Lourie O, Dyer MJ, Moloni K, Kelly TF, Ruoff RS. Science 2000, 287, 637-640.

[3] Demczyk BG, Wang YM, Cumings J, Hetman M, Han W, Zettl A, Ritchie RO. Mater. Sci. Eng. A 2002, 334, 173-178.

[4] Tjong SC. Carbon Nanotube Reinforced Composites: Metal and Ceramic Matrices, Wiley: New York, 2009.

[5] Coleman JN, Khan U, Blau WJ, Gun'ko YK. Carbon 2006, 44, 1624-1652. 
[6] Ci L, Suhr J, Pushparaj V, Zhang X, Ajayan PM. Nano Lett. 2008, 8, 2762-2766.

[7] Thostenson ET, Chou TW. J. Phys. D: Appl. Phys. 2002, 35, L77.

[8] Esawi AMK, Farag MM. Mater. Des. 2007, 28, 2394-2401.

[9] Xiang J, Xie L, Meguid SA, Pang S, Yi J, Zhang Y, Liang R. Comput. Mater. Sci. 2017, 128, 359-372.

[10] Alva A, Bhagat A, Raja S. Mech. Adv. Mater. Struct. 2015, 22, 819-828.

[11] Ansari R, Hassanzadeh Aghdam MK. Compos. Part B: Eng. 2016, 90, 512-522.

[12] Ansari R, Hassanzadeh Aghdam MK, Mahmoodi MJ. Acta Mech. 2016, 227, 3475-3495.

[13] Arash B, Wang Q, Varadan VK. Sci. Rep. 2014, 4, 6479.

[14] Kundalwal SI, Ray MC. Compos. Part B: Eng. 2014, 57, 199-209.

[15] Abdollahzadeh Shahrbabaki E, Alibeigloo A. Compos. Struct. 2014, 111, 362-370.

[16] Lin F, Xiang Y. Appl. Mech. Mater. 2014, 553, 681-686.

[17] Ansari R, Faghih Shojaei M, Mohammadi V, Sadeghi F. Compos. Struct. 2014, 113, 316-327.

[18] Wu HL, Yang J, Kitipornchai S. Thin-Walled Struct. 2016, 108, 225-233.

[19] Ansari R, Shahabodini A, Faghih Shojaei M. Compos. Struct. 2016, 139, 167-187.

[20] Ansari R, Pourashraf T, Gholami R, Shahabodini A. Compos. Part B: Eng. 2016, 90, 267-277.

[21] Ghorbani Shenas A, Malekzadeh P, Ziaee S. Compos. Struct. 2017, 162, 325-340.

[22] Ansari R, Hasrati E, Faghih Shojaei M, Gholami R, Shahabodini A. Physica E 2015, 69, 294-305.

[23] Mercan K, Ersoy H, Civalek Ö. J. Appl. Comput. Mech. 2016, 2, 128-133.
[24] Civalek Ö. J. Compos. Mater. 2008, 42, 2853-2867.

[25] Demir Ç, Ersoy H, Mercan K, Civalek Ö. Curved Layer Struct. 2017, 4, 146-157.

[26] Thostenson ET, Li WZ, Wang DZ, Ren ZF, Chou TW. J. Appl. Phys. 2002, 91, 6034

[27] Bekyarova E, Thostenson ET, Yu A, Kim H, Gao J, Tang J, Hahn HT, Chou TW, Itkis ME, Haddon RC. Langmuir 2007, 23, 3970-3974.

[28] Al-Haik M, Luhrs CC, Reda Taha MM, Roy AK, Dai L, Phillips J, Doorn S. J. Nanotechnol. 2010, 2010, 860178.

[29] Tehrani M, Safdari M, Boroujeni AY, Razavi Z, Case SW, Dahmen K, Garmestani H, Al-Haik MS. Nanotechnology 2013, 24, 155704.

[30] Pal G, Kumar S. Mater. Des. 2016, 89, 129-136.

[31] Alipour Skandani A, Al-Haik M. Compos. Part B 2016, 99, 63-74.

[32] Abdelal N, Taamneh Y. Desalination 2017, 419, 117-124.

[33] Ahmadi M, Ansari R, Rouhi H. Physica E 2017, 93, 17-25.

[34] Odegard GM, Clancy TC, Gates TS. Polymer 2005, 46, 553-562.

[35] Tsai JL, Tzeng SH, Chiu YT. Compos. Part B 2010, 41, 106-115.

[36] Shen L, Li J. Phys. Rev. B 2004, 69, 045414.

[37] Shen L, Li J. Phys. Rev. B 2005, 71, 035412.

[38] Liu JZ, Zheng QS, Wang LF, Jiang Q. J. Mech. Phys. Solids 2005, 53, 123-142.

[39] Kulkarni M, Carnahan D, Kulkarni K, Qian D, Abot JL. Compos. Part B: Eng. 2010, 41, 414-421.

[40] Lopez Manchado MA, Valentini L, Biagiotti J, Kenny JM. Carbon 2005, 43, 1499-1505.

[41] Selmi A, Friebel C, Doghri I, Hassis H. Compos. Sci. Technol. 2007, 67, 2071-2084. 